\title{
European adolescents' level of perceived stress is inversely related to their diet quality: the Healthy Lifestyle in Europe by Nutrition in Adolescence study
}

\author{
Tineke De Vriendt ${ }^{1,2 *}$, Els Clays ${ }^{1}$, Inge Huybrechts ${ }^{1}$, Ilse De Bourdeaudhuij ${ }^{3}$, Luis A. Moreno ${ }^{4}$, \\ Emma Patterson ${ }^{5}$, Dénes Molnár ${ }^{6}$, María I. Mesana ${ }^{4}$, Laurent Beghin ${ }^{7,8}$, Kurt Widhalm ${ }^{9}$, Yannis Manios ${ }^{10}$ \\ and Stefaan De Henauw ${ }^{1,11}$ on behalf of the HELENA Study Group \\ ${ }^{1}$ Department of Public Health, Faculty of Medicine and Health Sciences, Ghent University, De Pintelaan 185-2 Blok A, \\ B-9000 Ghent, Belgium \\ ${ }^{2}$ Research Foundation Flanders, Egmontstraat 5, B-1000 Brussels, Belgium \\ ${ }^{3}$ Department of Movement and Sports Sciences, Faculty of Medicine and Health Sciences, Ghent University, \\ Watersportlaan 2, B-9000 Ghent, Belgium \\ ${ }^{4}$ Growth, Exercise, Nutrition and Development (GENUD) Research Group, School of Health Science (EUCS), \\ University of Zaragoza, Domingo Miral s/ $n$, 50009 Zaragoza, Spain \\ ${ }^{5}$ Unit for Preventive Nutrition, Department of Biosciences and Nutrition, Karolinska Institutet, SE-141 57, Huddinge, Sweden \\ ${ }^{6}$ Department of Pediatrics, Medical Faculty, University of Pécs, Jzsef A 7, 7623 Pécs, Hungary \\ ${ }^{7}$ Inserm U955, IFR114, Faculty of Medicine, University Lille 2, F-59037 Lille, France \\ ${ }^{8}$ CIC-9301-CHEU-Inserm of Lille, CHRU de Lille, F-59037 Lille, France \\ ${ }^{9}$ Department of Pediatrics and Adolescent Medicine, Medical University of Vienna, Währinger Gürtel 18-20, A-1090 Vienna, \\ Austria \\ ${ }^{10}$ Department of Nutrition \& Dietetics, Harokopio University, 70 El. Venizelou Avenue, 17671 Kallithea, Athens, Greece \\ ${ }^{11}$ Department of Health Sciences, Vesalius, University College Ghent, Keramiekstraat 80, B-9000 Ghent, Belgium \\ (Submitted 20 May 2011 - Final revision received 19 September 2011 - Accepted 19 September 2011 - First published online 4 November 2011)
}

\section{Abstract}

As stress is hypothesised to influence dietary behaviour, the relationship between perceived stress and diet quality in European adolescents was investigated. Within the Healthy Lifestyle in Europe by Nutrition in Adolescence study, adolescents ( $n$ 704, aged $12-17$ years) from schools in five European cities (Ghent, Stockholm, Zaragoza, Athens and Vienna) completed a $2 \mathrm{~d} 24 \mathrm{~h}$ dietary recall assessment and an Adolescent Stress Questionnaire. Measurements and information were taken on height, weight, pubertal stage, parental education level, the level of moderate-to-vigorous physical activity (MVPA) and sleep duration. The Diet Quality Index for Adolescents (DQI-A) was calculated from the dietary data, which comprised three components reflecting dietary diversity, quality and equilibrium. Hierarchical linear models were performed to investigate the relationship between the adolescents' level of perceived stress and the DQI-A and its components, adjusting for relevant covariates (age, BMI $z$-score, pubertal stage and parental education). These models were additionally adjusted for MVPA or sleep duration. In both boys and girls, perceived stress was a significant independent negative predictor for their overall DQI-A. This inverse relationship was observed for all dietary components, except for dietary diversity in boys, and it was unaltered when additionally adjusted for MVPA or sleep duration. The observed inverse relationship between stress and diet quality within these European adolescents supports the hypothesis that stress influences dietary behaviour, thus emphasising the need for preventive stresscoping strategies for adolescents.

\section{Key words: Perceived stress: Adolescence: Diet quality index: Dietary restraint}

The importance of balanced dietary habits for human health is widely accepted and thus acknowledged in many health promotion campaigns worldwide ${ }^{(1,2)}$. The foundations of health-related behaviour, such as balanced dietary habits, are established during early stages of childhood and adolescence, and they continue during adulthood ${ }^{(3)}$. Major concerns about the current adolescent diet include an inadequate intake of fruit, vegetables and dairy products ${ }^{(4)}$. The current trends

Abbreviations: ASQ, Adolescent Stress Questionnaire; CSS, cross-sectional study; DIAT, Dietary Assessment Tool; DQI-A, Diet Quality Index for Adolescents; HELENA, Healthy Lifestyle in Europe by Nutrition in Adolescence; HLM, hierarchical linear models; MVPA, moderate-to-vigorous physical activity; SES, socio-economic status.

* Corresponding author: T. De Vriendt, fax +32 93324994, email tineke.devriendt@ugent.be 
in their dietary patterns, such as increased snacking, eating meals outside the home, and the consumption of fast food and sweetened energy beverages, decrease their dietary quality and favour the development of obesity ${ }^{(5)}$. The adolescent's diet is influenced by several personal and sociodemographic characteristics (e.g. food preferences, sex, education, socioeconomic status (SES), origin), as well as social and environmental factors, such as food in the home environment and parental dietary behaviour, as well as the availability of fastfood shops and restaurants ${ }^{(6-9)}$.

Chronic stress has recently been documented as being involved in the aetiology of obesity, partly by influencing dietary behaviour ${ }^{(10)}$. Chronic stress has been hypothesised to stimulate the consumption of 'comfort foods', which are energy-dense due to their high sugar and fat contents ${ }^{(11)}$. Epidemiological and experimental studies have shown that stress can both raise and reduce appetite ${ }^{(12-14)}$, and change food selection into more unhealthy ones (more crisps, candy, biscuits or fast food, and less fruit and vegetables) in women ${ }^{(15-18)}$, but not in men ${ }^{(17,19)}$. People with a restrained attitude towards eating also seem to be most sensitive to stress-induced eating ${ }^{(2)}$, which has already been verified in pre-adolescents ${ }^{(21)}$ and adults ${ }^{(18)}$. Other important factors to consider with respect to the relationship between stress and dietary behaviour are the levels of physical activity and sleep, as these are both potentially related to stress and dietary behaviour ${ }^{(22-25)}$. Epidemiological research investigating the influence of stress on the diet of adolescents is rather scarce and mostly involves small populations ${ }^{(26)}$, specific adolescent populations (e.g. black adolescents from Cleveland ${ }^{(26)}$ or mostly Latino ethnicity ${ }^{(27)}$ ) and/or certain aspects of the diet (e.g. fatty foods, fruit or vegetable intake, snacking, breakfast consumption $^{(28)}$, emotional eating $\left.{ }^{(27)}\right)$. In recent years, the importance of considering the overall diet quality (and not only parts of it) in nutrition research has been emphasised ${ }^{(29)}$. In response to this, several indices of overall diet health have been developed to evaluate simultaneously several aspects of the individual's diet ${ }^{(30,31)}$.

The present study was undertaken to meet the shortcomings in this research area by investigating the relationship between the level of perceived stress and the overall diet quality in a large multinational sample of European adolescents. Additionally, we examined whether this relationship was independent of the level of physical activity and sleep duration.

\section{Methods}

\section{Study design and population}

The study was part of a European project called HELENA (Healthy Lifestyle in Europe by Nutrition in Adolescence). The aim of the cross-sectional part of HELENA (HELENACSS) was to obtain reliable and comparable data from a selected cohort of European adolescents on a broad variety of parameters related to nutrition, health, physical activity and fitness ${ }^{(32)}$. A random cluster sampling of $>3000$ adolescents, stratified by geographical location, age and SES, was carried out, whereby all pupils from a selection of classes from all schools in ten European cities were invited to participate. All participants and their parents gave written informed consent to participate. A total of 3865 adolescents participated in the HELENA-CSS, of which 3528 adolescents were eligible for inclusion (they provided written informed consent, were not participating in another survey, were aged between 12.5 and 17.5 years, and data on sex, height and weight were available). A detailed description of the sampling and recruitment procedure of the HELENA-CSS and the eligibility criteria has previously been outlined ${ }^{(33)}$.

The non-intervening, epidemiological character of HELENA made it possible to assess naturally occurring perceived stress on a large sample of adolescents across Europe. The ten cities involved in the HELENA-CSS were invited for participation in the stress substudy, of which six (Ghent, Belgium; Stockholm, Sweden; Vienna, Austria; Pecs, Hungary; Athens, Greece; Zaragoza, Spain) actually participated. Of the 2177 eligible adolescents from these six cities, a sample size of 1240 adolescents, selected on class level, did in fact participate in the stress substudy. The reason for this sample reduction was that the stress module was optional and omitted when fieldworkers were constrained by time limits or logistics.

\section{Procedures}

The HELENA study was conducted according to the guidelines laid down in the Declaration of Helsinki, and the project protocol was approved by the Ethics Committees of all the participating cities ${ }^{(34)}$. The fieldwork was carried out from October 2006 to December 2007 and consisted of a clinical examination, physical activity and fitness assessment, blood sampling (of only one-third of the participants), assessment of dietary intake and sociodemographic background, and different aspects of nutrition and physical activity via questionnaires ${ }^{(32)}$. The fieldwork was fully standardised across the cities and was conducted in the school during school hours. During the clinical examination, the adolescents' height, weight and pubertal stage were assessed. Specific questionnaires (details of these questionnaires are provided below), asking for the adolescents' level of perceived stress, their social background, sleep duration and level of physical activity, were completed in a classroom setting in total silence and fully supervised to avoid between-subject interaction. Data on the dietary intakes of the adolescents were obtained from a self-administered computerised $2 \mathrm{~d} 24 \mathrm{~h}$ dietary recall method, called HELENA-DIAT ${ }^{(35,36)}$, which took place in a computer classroom of the schools.

\section{Measurements}

Personal and sociodemographic data. The adolescents' pubertal stage, height and weight were assessed following standard procedures ${ }^{(37)}$. Measurements of height and weight were parts of the basic criteria to be included in the HELENA-CSS (see above). Height was measured with a stadiometer (type SECA 225) to the nearest $0 \cdot 1 \mathrm{~cm}$ and weight was measured to the nearest $0 \cdot 1 \mathrm{~kg}$ using electronic scales (type SECA 861). BMI was calculated as weight ( $\mathrm{kg}$ ) divided by

was cartied out, whereby all pupils from a selection of classes 
the squared height $\left(\mathrm{m}^{2}\right)$. The corresponding $z$-score relative to the British 1990 Growth Chart References was determined to obtain comparable values across both sexes and all ages ${ }^{(38)}$.

Parental education. The SES questionnaire assessed the level of education attained by each parent. Adolescents selected one of the following levels: (1) elementary education, (2) lower secondary education, (3) higher secondary education, or (4) tertiary education (specialisation/college/university degree $)^{(39)}$. Parental education might be considered an appropriate indicator of socio-economic status ${ }^{(40)}$. For statistical analyses, only the highest level of both parental education levels was considered and adolescents were divided into two parental educational categories, namely lower parental education (up to higher secondary education) and higher parental education (above higher secondary education).

Perceived stress. The Adolescent Stress Questionnaire (ASQ) consists of fifty-six items, divided into ten component scales, covering the broad dimensions of adolescent stress exposure (stress of home life, school performance, school attendance, romantic relationships, peer pressure, teacher interaction, future uncertainty, school/leisure conflict, financial pressure and emerging adult responsibility ${ }^{(41,42)}$. The English version of the ASQ was translated in duplicate to the native languages of the participating cities (Dutch, Swedish, Spanish, German, Greek and Hungarian). These two versions were compared to identify translation errors. The translated questionnaire was translated back to English and compared with the original version to check for remaining transliteration errors. Respondents were asked to answer each item on a sixpoint Likert scale ( $1=$ 'Not at all stressful', $2=$ 'A little stressful', $3=$ 'Moderately stressful', $4=$ 'Quite stressful', $5=$ 'Very stressful', $6=$ 'Is irrelevant to me'). A procedure for excluding under-reporters was applied: questionnaires with more than four missing scales (due to a missing value) or with more than one missing value for one of the scales were excluded from further analysis. Questionnaires with $50 \%$ or more of the answers being 'Is irrelevant to me' were also excluded. Answers 1 to 5 got the respective score (1-5) and answer 6 was scored as zero. A stress score, reflecting the overall level of perceived adolescent stress, was obtained by adding up the individual scores of all fifty-six items. The reliability of the ASQ stress score for use in our European adolescent population was checked and found to be sufficient (Cronbach's $\alpha=0.95$; test-retest intraclass correlation coefficient $=0 \cdot 89, P<0 \cdot 001)^{(42)}$.

Healthy Lifestyle in Europe by Nutrition in AdolescenceDietary Assessment Tool. The HELENA-DIAT was developed on the basis of similar software that had previously been designed for Flemish adolescents (Young Adolescents' Nutrition Assessment on Computer $)^{(35,36)}$. It is based on six meal occasions (breakfast, morning snack, lunch, afternoon snack, dinner and evening snack) on the previous day ${ }^{(36)}$. The HELENA-DIAT showed good agreement with an intervieweradministered HELENA-DIAT interview and proved to be a good and user-friendly method for collecting detailed dietary information from adolescents ${ }^{(35,36)}$. After a short introduction given by a trained researcher and/or dietitian on how to carry out the HELENA-DIAT, the adolescents completed the
HELENA-DIAT; they were allowed to ask questions or request assistance. After completion, the trained researcher/dietitian checked the input for completeness and correctness. The adolescents completed the HELENA-DIAT twice on two different non-consecutive weekdays within a time span of 2 weeks. The dietary assessment was only considered valid for statistical analysis when data for $2 \mathrm{~d}$ were provided. The intake of foods was aggregated to the intake of eleven food groups based on the Flemish food-based dietary guidelines ${ }^{(43)}$, namely (1) water, (2) bread and cereal, (3) grains and potatoes, (4) fruit, (5) vegetables, (6) milk (drinks), milk desserts and yogurt, (7) cheese, (8) meat/fish/eggs/vegetarian substitutes, (9) spread and cooking fat, (10) low-nutrient, energy-dense foods (e.g. chocolate, sugar products, biscuits, pies, savoury snacks, creams, confectionery) and (11) low-nutrient, energy-dense drinks (e.g. carbonated soft drinks, juices, alcoholic drinks). The individual food group intakes for the $2 \mathrm{~d}$ were averaged for further analysis. An overall index of diet quality, the Diet Quality Index for Adolescents (DQI-A), was calculated. The design of the DQI-A is based on a previous DQI that had been developed for preschool children ${ }^{(31)}$ Preliminary analyses showed that the DQI-A was associated with a better macro- and micronutrient intake and a better blood profile of vitamin $\mathrm{D}$ and active vitamin $\mathrm{B}_{12}$, indicative of a good validity in adolescents (E Cruz Fernandez and $\mathrm{K}$ Vyncke, unpublished results). The DQI-A represents the arithmetic mean of three individual components, namely dietary (1) diversity, (2) quality and (3) equilibrium. These reflect three different dietary habit aspects, whereas the DQI-A is an indicator of overall diet quality. Each of the components has its strengths and limitations, but they contain complementary information and are therefore combined in the DQI-A. 'Dietary diversity' indicates to what extent foods of the aforementioned food groups are consumed (two groups of low-nutrient, energy-dense foods and drinks not being considered), without taking into account the amounts of foods. It is a rough measure of diet quality, which is particularly sensitive to non-consumption of one of the essential food groups. 'Dietary quality' expresses whether the child makes the optimal food quality choices. To calculate this dietary quality score, the consumed foods have been categorised into three groups, i.e. food items that are favoured in the 'preference group' (e.g. fresh fruit and cereal/brown bread); food items that may be consumed in the 'moderation group' (e.g. white bread); and food items that should be avoided in the 'low-nutrient, energy-dense group' (e.g. soft drinks and sweet snacks). All food amounts were multiplied with a factor that was assigned to each quality category: 1 for items of the 'preference group'; 0 for items to be consumed with 'moderation'; and -1 for items of the 'low-nutrient, energydense group'. These values were summed and divided by the total amount of food consumed. 'Dietary equilibrium' indicates to what extent the consumed portion sizes of the different food groups correspond to the daily quantities recommended in the food-based dietary guidelines ${ }^{(43)}$, taking into account both under- and over-consumption. The two components, dietary diversity and dietary equilibrium, can range between $0 \%$ (very poor diversity or equilibrium) 
and $100 \%$ (perfect diversity or equilibrium), while the dietary quality component can range between $-100 \%$ (very poor quality) and $100 \%$ (perfect quality). No weighting factors were used when summing the scores of the individual components, making the DQI-A score a value ranging between -33.3 and $100 \%$.

Physical activity and sleep. The level of physical activity of the last $7 \mathrm{~d}$ was assessed with the International Physical Activity Questionnaire for Adolescents ${ }^{(44)}$. The content of the International Physical Activity Questionnaire for Adolescents, the procedure for calculating the total amount of minutes per week ( $\mathrm{min} /$ week) spent in moderate-to-vigorous physical activity (MVPA), and its validity have been published ${ }^{(44)}$. The adolescents' self-reported sleep duration during weekdays and weekend days was inquired with a sedentary questionnaire. These two values were averaged ( $\mathrm{h} /$ night), taking into account the number of weekdays and weekend days.

\section{Data analysis}

Only adolescents with a valid ASQ and valid dietary intake data were included in the present study ( $n$ 704). The characteristics of the sample for statistical analyses were compared with the total eligible HELENA sample of the six cities, using independent-samples $t$ tests for continuous variables and Pearson's $\chi^{2}$ tests for categorical variables. The characteristics of the boys and girls were described as means and standard deviations or proportions (absolute numbers and percentages), and sex differences in these characteristics were investigated. As independent-samples $t$ tests revealed significantly higher scores on the DQI-A, including each individual component, in the adolescent girls compared with the boys (Table 1), further analyses were stratified for sex. The relationship between the level of perceived stress and diet quality was investigated using hierarchical linear models (HLM), with the cities and schools as subject grouping variables since cases were nested within these cities and schools. These models were controlled for relevant covariates (age, BMI $z$-score, pubertal stage and parental education). In the next step, the HLM were additionally adjusted for MVPA and the average sleep duration to examine whether these potential covariates confounded the relationship between stress and diet quality. The Statistical Package for the Social Sciences (SPSS) version 15 (SPSS, Inc., Chicago, IL, USA) was used for statistical analyses. A threshold of $P<0.05$ was considered significant.

\section{Results}

A total of 1073 out of 2177 eligible adolescents from the six participating cities completed a valid ASQ, from which the level of stress could be calculated. Of these, 704 adolescents provided valid dietary data for $2 \mathrm{~d}$ and were included for analysis. The main reason for this large dropout was first due to there being no dietary intake data available for the adolescents from Pécs (due to logistical problems; $n$ 206). Second, due to the labour-intensiveness of the $2 \mathrm{~d} 24 \mathrm{~h}$ recall dietary assessment, several adolescents did not meet the criteria for validity (provided records on $2 \mathrm{~d} ; n$ 163). Comparison of the sample used for statistical analyses ( $n$ 704) with the total eligible sample of the six participating cities ( $n$ 2177) gave significant differences in BMI $z$-score $(0 \cdot 21 v \cdot 0 \cdot 41 ; P<0 \cdot 001)$, sex distribution (larger proportion of girls in the studied sample; $P<0 \cdot 001$ ), level of parental education (larger proportion of higher parental education in the studied sample; $P<0.001)$ and DQI-A (55.7 v. 53.6; $P=0.004)$, whereas their age $(14.8$ $v$. 14.8 years; $P=0.259)$ and distribution across pubertal stages $(P=0 \cdot 130)$ were comparable. The stress score of the studied sample did not differ significantly from the total sample that provided a valid ASQ ( $n$ 1073).

The population characteristics for the boys ( $n$ 270) and girls ( $n$ 434) are presented in Table 1 . As previously recorded, the DQI-A and its components (dietary diversity, quality and equilibrium) were significantly lower in boys compared with girls. The girls were also slightly older, had higher stress scores, a lower level of MVPA and a shorter sleep duration compared with boys, while their BMI $z$-scores were comparable. Additionally, significant sex differences were found for the distribution across city of origin and pubertal stage, but not for parental education.

Before establishing the full HLM, intercept-only models were performed to investigate the proportional variance explained by the cities and schools as grouping variables. The proportional variance of the DQI-A and its components declared by 'city' as the grouping variable varied from $2 \cdot 1$ to $10.9 \%$, except for dietary equilibrium in girls, where the proportional variance was $0 \%$. For 'school', the proportional variance varied from 3.4 to $21.0 \%$. In general, these variances confirmed the clustering of cases within these grouping variables and justified the use of the HLM. Results of the HLM with the DQI-A or one of its components as dependent and the stress score as independent - adjusted for age, BMI $z$-score, pubertal stage and parental education - are presented separately in Table 2 for boys and girls (model 1). In both boys and girls, their stress score was a significant negative predictor of their overall diet quality. In girls, this inverse association was reflected in their dietary diversity and quality, whereas it was of borderline significance for dietary equilibrium. In boys, the inverse relationship was reflected in their dietary quality and equilibrium. The boys' BMI $z$-score and age were independent positive and negative predictors, respectively, of their diet quality. In girls, their diet quality was only positively related to the level of parental education.

Next, the HLM were additionally adjusted for the level of MVPA (Table 2, model 2) and the average sleep duration (Table 2, model 3). As the interactions between the stress score and these covariates were not significant (data not shown), interaction terms were left out. In both boys and girls, the level of MVPA did not significantly contribute to the variance in DQI-A or its components, whereas sleep duration was positively related to overall diet quality and one or more components. When repeating the HLM for dietary equilibrium in girls without the non-significant covariates (age, BMI $z$-score, pubertal stage, MVPA and sleep duration), perceived stress became a significant independent negative predictor $(B=-0 \cdot 02 ; P=0 \cdot 040)$. 
Table 1. Description of the characteristics of the participating adolescent boys and girls (Number of participants, percentages, mean values and standard deviations)

\begin{tabular}{|c|c|c|c|c|c|c|c|}
\hline \multirow[b]{2}{*}{ Characteristics } & \multicolumn{2}{|c|}{$\begin{array}{c}\text { Total sample } \\
(n \text { 704) }\end{array}$} & \multicolumn{2}{|c|}{$\begin{array}{l}\text { Boys } \\
(n \text { 270) }\end{array}$} & \multicolumn{2}{|c|}{$\begin{array}{l}\text { Girls } \\
(n \text { 434) }\end{array}$} & \multirow[b]{2}{*}{$P^{*}$} \\
\hline & $n$ & $\%$ & $n$ & $\%$ & $n$ & $\%$ & \\
\hline Age (years) & \multirow{2}{*}{\multicolumn{2}{|c|}{14.81}} & & & & & 0.006 \\
\hline Mean & & & \multicolumn{2}{|c|}{14.65} & \multicolumn{2}{|c|}{14.91} & \\
\hline SD & \multicolumn{2}{|c|}{$1 \cdot 2$} & \multicolumn{2}{|c|}{$1 \cdot 2$} & \multicolumn{2}{|c|}{$1 \cdot 2$} & \\
\hline BMI $z$-score & & & & & & & 0.722 \\
\hline Mean & \multicolumn{2}{|c|}{0.21} & \multicolumn{2}{|c|}{0.23} & \multicolumn{2}{|c|}{0.20} & \\
\hline SD & \multicolumn{2}{|c|}{1.0} & \multicolumn{2}{|c|}{1.1} & \multicolumn{2}{|c|}{1.0} & \\
\hline \multicolumn{7}{|l|}{ City of origin } & 0.005 \\
\hline Stockholm & 221 & 31.4 & 75 & $27 \cdot 8$ & 146 & 33.6 & \\
\hline Ghent & 272 & $38 \cdot 6$ & 114 & $42 \cdot 2$ & 158 & 36.4 & \\
\hline Vienna & 39 & 5.5 & 7 & $2 \cdot 6$ & 32 & 7.4 & \\
\hline Zaragoza & 141 & $20 \cdot 0$ & 65 & $24 \cdot 1$ & 76 & 17.5 & \\
\hline Athens & 31 & 4.4 & 9 & 3.3 & 22 & $5 \cdot 1$ & \\
\hline \multicolumn{7}{|l|}{ Pubertal stage } & 0.016 \\
\hline Stage I & 3 & 0.4 & 3 & $1 \cdot 1$ & 0 & 0.0 & \\
\hline Stage II & 40 & $5 \cdot 7$ & 22 & $8 \cdot 1$ & 18 & $4 \cdot 1$ & \\
\hline Stage III & 125 & $17 \cdot 8$ & 40 & $14 \cdot 8$ & 85 & $19 \cdot 6$ & \\
\hline Stage IV & 250 & 35.5 & 91 & 33.7 & 159 & $36 \cdot 6$ & \\
\hline Stage V & 257 & 36.5 & 102 & 37.8 & 155 & $35 \cdot 7$ & \\
\hline Missing & 29 & $4 \cdot 1$ & 12 & $4 \cdot 4$ & 17 & 3.9 & \\
\hline \multicolumn{7}{|l|}{ Parental education } & 0.072 \\
\hline Lower & 248 & $35 \cdot 2$ & 85 & 31.5 & 163 & $37 \cdot 6$ & \\
\hline Higher & 429 & $60 \cdot 9$ & 177 & $65 \cdot 6$ & 252 & $58 \cdot 1$ & \\
\hline Missing & 27 & $3 \cdot 8$ & 8 & $3 \cdot 0$ & 19 & 4.4 & \\
\hline \multicolumn{7}{|l|}{ Stress score } & 0.003 \\
\hline Mean & \multicolumn{2}{|c|}{123.43} & & & & & \\
\hline SD & & & & & & & \\
\hline DQI-A & & & & & & & $<0.001$ \\
\hline Mean & & & & & & & \\
\hline SD & & & & & & & \\
\hline Dietary diversity & & & & & & & 0.005 \\
\hline Mean & & & & & & & \\
\hline SD & & & & & & & \\
\hline Dietary quality & & & & & & & 0.008 \\
\hline Mean & & & & & & & \\
\hline SD & & & & & & & \\
\hline Dietary equilibrium & & & & & & & $<0.001$ \\
\hline Mean & & & & & & & \\
\hline SD & & & & & & & \\
\hline Level of MVPA (min/week) & & & & & & & $<0.001$ \\
\hline Mean & & & & & & & \\
\hline SD & & & & & & & \\
\hline Sleep duration (h/night) & & & & & & & 0.006 \\
\hline Mean & & & & & & 02 & \\
\hline SD & & & & & & & \\
\hline
\end{tabular}

\section{Discussion}

The present study examined for the first time the relationship between perceived stress and diet quality in a large-scale multinational sample of adolescents. The results demonstrated an inverse relationship between the level of perceived stress and the overall diet quality in the European adolescent population, and this inverse relationship was independent of their level of physical activity and their sleep duration. In girls, this inverse relationship was present for all three components of diet quality (for dietary equilibrium only after omitting non-significant covariates), suggesting that perceived stress might simultaneously impair their diversity in food groups, the quality of the chosen foods and the extent of meeting the food-based dietary guidelines. In boys, however, this inverse association was only reflected in the extent to which they met the foodbased dietary guidelines and in the quality of the chosen foods. While the level of physical activity was not an independent predictor of their diet quality, their sleep duration was an independent negative predictor, supporting the hypothesis that sleep duration influences partially the risk of obesity by its influence on dietary behaviour ${ }^{(25)}$.

Previous research on stress and diet quality in adolescents is scarce. In one study, stress had no direct effect on eating behaviour, but this was largely attributed to the methodological limitations of the stress assessment ${ }^{(45)}$. In twenty-five black adolescents from Cleveland, a significant negative correlation 
Table 2. Hierarchical linear models (HLM) investigating the relationship between perceived stress and diet quality in European adolescent boys and girls

\begin{tabular}{|c|c|c|c|c|c|c|c|c|}
\hline \multirow[b]{3}{*}{ HLM-independent } & \multicolumn{8}{|c|}{ HLM-dependent } \\
\hline & \multicolumn{2}{|c|}{ DQI-A } & \multicolumn{2}{|c|}{ Diversity } & \multicolumn{2}{|c|}{ Quality } & \multicolumn{2}{|c|}{ Equilibrium } \\
\hline & $B$ & $P$ & $B$ & $P$ & $B$ & $P$ & $B$ & $P$ \\
\hline \multicolumn{9}{|l|}{ Boys } \\
\hline \multicolumn{9}{|l|}{ Model 1} \\
\hline Stress score & -0.06 & 0.007 & -0.04 & 0.081 & -0.11 & 0.030 & -0.04 & 0.007 \\
\hline Age (years) & -2.08 & 0.017 & -0.75 & 0.340 & -4.06 & 0.033 & -1.44 & 0.012 \\
\hline BMI $z$-score & 3.17 & $<0.001$ & 0.38 & 0.640 & $7 \cdot 10$ & $<0.001$ & 2.09 & $<0.001$ \\
\hline Pubertal stage & 1.49 & 0.182 & 1.47 & 0.144 & $2 \cdot 11$ & 0.384 & 1.06 & 0.142 \\
\hline Parental education* & -3.28 & 0.107 & -2.08 & 0.260 & -5.91 & 0.182 & -1.71 & 0.199 \\
\hline \multicolumn{9}{|l|}{ Model 2} \\
\hline Stress score & -0.07 & 0.003 & -0.04 & 0.112 & -0.13 & 0.010 & -0.05 & 0.005 \\
\hline Age (years) & -1.96 & 0.027 & -0.57 & 0.479 & -4.02 & 0.034 & -1.34 & 0.023 \\
\hline BMI $z$-score & 3.04 & 0.001 & 0.40 & 0.637 & $6 \cdot 68$ & 0.001 & $2 \cdot 10$ & 0.001 \\
\hline Pubertal stage & 1.57 & 0.166 & 1.52 & 0.143 & 2.37 & 0.330 & 1.22 & 0.100 \\
\hline Parental education* & -2.97 & 0.158 & $-1 \cdot 70$ & 0.378 & $-5 \cdot 11$ & 0.255 & -1.64 & 0.234 \\
\hline MVPA (min/week) & 0.00 & 0.581 & 0.00 & 0.070 & 0.00 & 0.739 & 0.00 & 0.279 \\
\hline \multicolumn{9}{|l|}{ Model 3} \\
\hline Stress score & -0.06 & 0.006 & -0.04 & 0.069 & -0.11 & 0.025 & -0.04 & 0.009 \\
\hline Age (years) & -1.82 & 0.042 & -0.58 & 0.469 & -3.66 & 0.062 & -1.23 & 0.036 \\
\hline BMI $z$-score & 3.23 & $<0.001$ & 0.48 & 0.553 & 7.07 & $<0.001$ & $2 \cdot 22$ & $<0.001$ \\
\hline Pubertal stage & 1.43 & 0.199 & 1.53 & 0.131 & 1.79 & 0.462 & $1 \cdot 18$ & 0.104 \\
\hline Parental education* & -3.80 & 0.066 & -2.67 & 0.156 & $-6 \cdot 13$ & 0.174 & -2.31 & 0.088 \\
\hline Sleep (h/night) & 1.75 & 0.041 & 1.47 & 0.062 & 2.38 & 0.202 & 1.42 & 0.013 \\
\hline \multicolumn{9}{|l|}{ Girls } \\
\hline \multicolumn{9}{|l|}{ Model 1} \\
\hline Stress score & -0.04 & 0.005 & -0.03 & 0.029 & -0.08 & 0.011 & -0.02 & 0.051 \\
\hline Age (years) & 0.14 & 0.854 & 0.47 & 0.462 & -0.91 & 0.571 & 0.51 & 0.345 \\
\hline BMI $z$-score & -0.51 & 0.469 & -0.56 & 0.364 & -0.73 & 0.627 & -0.19 & 0.712 \\
\hline Pubertal stage & 1.57 & 0.191 & $-1 \cdot 14$ & 0.275 & 5.54 & 0.031 & 0.52 & 0.522 \\
\hline Parental education* & -3.09 & 0.035 & -3.37 & 0.008 & -4.58 & 0.139 & -1.92 & 0.072 \\
\hline \multicolumn{9}{|l|}{ Model 2} \\
\hline Stress score & -0.05 & 0.004 & -0.03 & 0.041 & -0.09 & 0.008 & -0.02 & 0.049 \\
\hline Age (years) & 0.20 & 0.804 & 0.50 & 0.451 & -0.85 & 0.612 & 0.53 & 0.343 \\
\hline BMI $z$-score & -0.64 & 0.372 & -0.74 & 0.244 & -0.94 & 0.538 & -0.22 & 0.677 \\
\hline Pubertal stage & 1.01 & 0.425 & -1.05 & 0.332 & 4.06 & 0.132 & 0.30 & 0.725 \\
\hline Parental education* & -2.84 & 0.057 & -3.48 & 0.007 & $-3 \cdot 72$ & 0.237 & -1.89 & 0.081 \\
\hline MVPA (min/week) & 0.00 & 0.340 & 0.00 & 0.702 & 0.01 & 0.179 & 0.00 & 0.775 \\
\hline \multicolumn{9}{|l|}{ Model 3} \\
\hline Stress score & -0.04 & 0.007 & -0.03 & 0.046 & -0.08 & 0.015 & -0.02 & 0.059 \\
\hline Age (years) & 0.36 & 0.641 & 0.64 & 0.328 & -0.52 & 0.753 & 0.67 & 0.231 \\
\hline BMI $z$-score & -0.52 & 0.468 & -0.54 & 0.384 & -0.73 & 0.634 & -0.21 & 0.686 \\
\hline Pubertal stage & $1 \cdot 70$ & 0.166 & -0.76 & 0.466 & $5 \cdot 53$ & 0.035 & 0.54 & 0.514 \\
\hline Parental education* & -3.14 & 0.037 & -3.20 & 0.014 & -4.89 & 0.126 & -1.92 & 0.077 \\
\hline Sleep (h/night) & 1.28 & 0.039 & $1 \cdot 19$ & 0.029 & 2.07 & 0.119 & 0.65 & 0.154 \\
\hline
\end{tabular}

DQI-A, Diet Quality Index for Adolescents; B, regression coefficient; MVPA, moderate-to-vigorous physical activity.

* 'Higher parental education' group is the reference category.

was observed between change in perceived stress and change in diet quality over 1 month in girls, but not in boys ${ }^{(26)}$. Greater stress was also associated with an unhealthier diet in a large-scale sample of young adolescent boys and girls from the $\mathrm{UK}^{(28)}$. Mikolajczyk et al. ${ }^{(17)}$ reported a sex difference in the association between perceived stress and dietary behaviour in young adults (mean age 20.6 years): in females, perceived stress was associated with unhealthy dietary behaviour, whereas this was not the case in their male counterparts. These findings and the slight sex difference in the present study suggest that sex difference in the relationship between stress and diet quality might evolve during the period of adolescence. Apart from this, the girls' diet quality, as well as their level of perceived stress, was significantly higher than in boys, but the influence of these higher values on the relationship between the two is difficult to evaluate.

The results of the present study are in agreement with the observed effects in adults, especially females, where stress increased food consumption and shifted their food choices into more unhealthy alternatives ${ }^{(18)}$. They are also in line with recently observed inverse associations between depressed mood and diet quality in adolescents ${ }^{(46)}$, and between mental health problems and healthy dietary patterns in early adolescents ${ }^{(47)}$, since life stress is a well-known predictor of depressed mood and psychological problems ${ }^{(48,49)}$. In addition, perceived stress has previously been demonstrated to be associated with emotional eating in adolescents $^{(27)}$, which in turn increases the consumption of energy-dense foods ${ }^{(50)}$. In short, stress might increase the 
feeling of depression, mental health problems and emotional eating, each affecting dietary quality. As adolescent girls are, in general, more sensitive to stress and its consequences (depression, psychological problems and emotional eating) ${ }^{(51,52)}$, this could explain why the observed relationship in the present study was slightly more consistent in girls compared with boys. This body of evidence supports the hypothesis that stress in adolescents stimulates the consumption of "comfort foods",(11); it emphasises the potential improper coping skills in adolescents under stress by taking up unhealthy dietary behaviours and highlights the importance of prevention campaigns to train adolescents in healthy strategies for coping with stress.

\section{Strengths and limitations}

Standardisation of the methodology and procedures across the participating cities, together with the large study sample, are important strengths of the present study. Unfortunately, our sample was not fully representative of Europe, as it was restricted to five geographical areas. Therefore, generalisation of the findings is limited to European adolescent populations from the participating cities, and thus research in other adolescents from the rest of the world is necessary.

The study faced a substantial sample reduction of the eligible HELENA population of the six cities as the stress substudy was optional and many adolescents did not provide valid dietary data. Subsequently, a selection bias might have been introduced because the proportion of females and adolescents with 'highly educated parents', as well as the BMI $z$-score and the overall diet quality, was higher in the sample used for statistical analyses than in the total eligible HELENA sample. The influence of this selection bias on the main findings is hard to evaluate, but it is presumed to be minimal as the analyses were stratified for sex, and the BMI $z$-score and parental education level were only considered as covariates.

The CSS design of HELENA does not look at any causal relationships. Previously, both the stress response and affective responses (emotions) were thought to be influenced by different food ingredients, while in turn stress and emotions can affect eating responses ${ }^{(53,54)}$. Future research is recommended on investigating prospective and reciprocal relationships between perceived stress and dietary quality in adolescents.

Data on diet quality, perceived stress and parental education were obtained by self-reports, which has well-known disadvantages (e.g. social desirability bias, under- or overreporting). However, the instruments have been tested and validated $^{(35,36,39,42)}$, anonymity was guaranteed and procedures for excluding under-reporters were employed. Exclusion of cases, together with the fact that the stress assessment was optional within the HELENA-CSS and thus not always performed, resulted in a considerable reduction in sample size, which could have affected the power of the statistical analyses and might have introduced some selection bias.

The HELENA-DIAT was completed on school days (Monday to Friday). The collected data referred to the food intake of the previous day, so only Sundays to Thursdays were considered and no food intake data were collected from Fridays and Saturdays. This could have affected the food intake data, as sometimes people may have certain rituals involving food on these days (e.g. fish on Fridays, pasta on Saturdays).

The present study examined whether the level of physical activity or the amount of sleep confounded the relationship between perceived stress and diet quality in adolescents. Apart from these two aspects, no other potential behavioural confounders were investigated. Previous evidence showed that dietary restraint moderated the relationship between stress and dietary behaviour ${ }^{(21)}$, so future research is recommended to investigate the potential role of dietary restraint in this context.

\section{Conclusions}

In this multi-centre sample of European adolescents, an inverse relationship was observed between the adolescents' level of perceived stress and their overall diet quality, independent of their level of physical activity and sleep duration. In both boys and girls, perceived stress was inversely related to their dietary quality and the extent of consuming recommended amounts of foods, while the girls' level of perceived stress was also associated with a less diverse food consumption pattern. The observed negative relationship gives support to the hypothesis that stress might influence adolescents' dietary behaviour by decreasing their diet quality, and emphasises the requirement for effective prevention campaigns to train adolescents in healthy strategies for coping with stress. Future research is recommended to investigate the long-term effects of stress on diet quality during adolescence and later adulthood.

\section{Acknowledgements}

The authors wish to thank the participating schools, adolescents and parents for their voluntary participation to the HELENA study. The authors also wish to acknowledge D. Byrne for his permission to use the Adolescent Stress Questionnaire. The HELENA study was supported by the European Community Sixth RTD Framework Programme (Contract FOOD-CT-2005-007034). The content of this article reflects only the authors' views and the European Community is not liable for any use that may be made of the information contained therein. This study was also supported by the Research Foundation - Flanders (grant no. 1.1.746.09.N.01 to T. D. V.) and by the Spanish Ministry of Health: Maternal, Child Health and Development Network (grant no. RD08/0072 to L. A. M.). The authors' contributions were as follows: T. D. V. and S. D. H. developed the design of the stress measurement. L. A. M. coordinated the HELENA project at the international level. L. A. M., I. D. B., D. M., K. W., Y. M. and S. D. H. were involved in the design of the HELENA project and locally coordinated the HELENA project. T. D. V., E. P., M. I. M. and L. B. organised the fieldwork and performed the data collection locally. I. H. was responsible for the database management and designed the DQI-A. E. C. and I. H. were involved in manuscript drafting and statistical analysis. All authors 
reviewed the manuscript, gave input and made significant improvements. All authors declare that they have no competing interests.

\section{HELENA Study Group}

Co-ordinator: Luis A. Moreno.

Core Group members: Luis A. Moreno, Fréderic Gottrand, Stefaan De Henauw, Marcela González-Gross, Chantal Gilbert.

Steering Committee: Anthony Kafatos (President), Luis A. Moreno, Christian Libersa, Stefaan De Henauw, Sara Castelló, Fréderic Gottrand, Mathilde Kersting, Michael Sjöstrom, Dénes Molnár, Marcela González-Gross, Jean Dallongeville, Chantal Gilbert, Gunnar Hall, Lea Maes, Luca Scalfi.

Project Manager: Pilar Meléndez.

Universidad de Zaragoza (Spain): Luis A. Moreno, Jesús Fleta, José A. Casajús, Gerardo Rodríguez, Concepción Tomás, María I. Mesana, Germán Vicente-Rodríguez, Adoración Villarroya, Carlos M. Gil, Ignacio Ara, Juan Revenga, Carmen Lachen, Juan Fernández Alvira, Gloria Bueno, Aurora Lázaro, Olga Bueno, Juan F. León, Jesús Mª Garagorri, Manuel Bueno, Juan Pablo Rey López, Iris Iglesia, Paula Velasco, Silvia Bel, Luis A. Gracia Marco, Theodora Mouratidou.

Consejo Superior de Investigaciones Cientificas (Spain): Ascensión Marcos, Julia Wärnberg, Esther Nova, Sonia Gómez, Ligia Esperanza Díaz, Javier Romeo, Ana Veses, Belén Zapatera, Tamara Pozo, David Martínez.

Université de Lille 2 (France): Laurent Beghin, Christian Libersa, Frédéric Gottrand, Catalina Iliescu, Juliana Von Berlepsch.

Research Institute of Child Nutrition Dortmund, Rheinische Friedrich-Wilhelms-Universität Bonn (Germany): Mathilde Kersting, Wolfgang Sichert-Hellert, Ellen Koeppen.

Pécsi Tudományegyetem (University of Pécs) (Hungary): Dénes Molnar, Eva Erhardt, Katalin Csernus, Katalin Török, Szilvia Bokor, Mrs Angster, Enikö Nagy, Orsolya Kovács, Judit Répasi.

University of Crete School of Medicine (Greece): Anthony Kafatos, Caroline Codrington, María Plada, Angeliki Papadaki, Katerina Sarri, Anna Viskadourou, Christos Hatzis, Michael Kiriakakis, George Tsibinos, Constantine Vardavas, Manolis Sbokos, Eva Protoyeraki, Maria Fasoulaki.

Institut für Ernährungs- und Lebensmittelwissenschaften Ernährungphysiologie. Rheinische Friedrich Wilhelms Universität (Germany): Peter Stehle, Klaus Pietrzik, Marcela González-Gross, Christina Breidenassel, Andre Spinneker, Jasmin Al-Tahan, Miriam Segoviano, Anke Berchtold, Christine Bierschbach, Erika Blatzheim, Adelheid Schuch, Petra Pickert.

University of Granada (Spain): Manuel J. Castillo, Ángel Gutiérrez, Francisco B. Ortega, Jonatan R. Ruiz, Enrique G. Artero, Vanesa España, David Jiménez-Pavón, Palma Chillón, Cristóbal Sánchez-Muñoz, Magdalena Cuenca.

Istituto Nazionalen di Ricerca per gli Alimenti e la Nutrizione (Italy): Davide Arcella, Elena Azzini, Emma Barrison, Noemi Bevilacqua, Pasquale Buonocore, Giovina Catasta, Laura Censi, Donatella Ciarapica, Paola D'Acapito, Marika Ferrari, Myriam Galfo, Cinzia Le Donne, Catherine Leclercq, Giuseppe Maiani, Beatrice Mauro, Lorenza Mistura, Antonella Pasquali,
Raffaela Piccinelli, Angela Polito, Raffaella Spada, Stefania Sette, Maria Zaccaria.

University of Napoli "Federico II" Dept of Food Science (Italy): Luca Scalfi, Paola Vitaglione, Concetta Montagnese.

Ghent University (Belgium): Ilse De Bourdeaudhuij, Stefaan De Henauw, Tineke De Vriendt, Lea Maes, Christophe Matthys, Carine Vereecken, Mieke de Maeyer, Charlene Ottevaere, Inge Huybrechts.

Medical University of Vienna (Austria): Kurt Widhalm, Katharina Phillipp, Sabine Dietrich, Birgit Kubelka Marion Boriss-Riedl.

Harokopio University (Greece): Yannis Manios, Eva Grammatikaki, Zoi Bouloubasi, Tina Louisa Cook, Sofia Eleutheriou, Orsalia Consta, George Moschonis, Ioanna Katsaroli, George Kraniou, Stalo Papoutsou, Despoina Keke, Ioanna Petraki, Elena Bellou, Sofia Tanagra, Kostalenia Kallianoti, Dionysia Argyropoulou, Katerina Kondaki, Stamatoula Tsikrika, Christos Karaiskos.

Institut Pasteur de Lille (France): Jean Dallongeville, Aline Meirhaeghe.

Karolinska Institutet (Sweden): Michael Sjöstrom, Jonatan R. Ruiz, Francisco B. Ortega, María Hagströmer, Anita Hurtig Wennlöf, Lena Hallström, Emma Patterson, Lydia Kwak, Julia Wärnberg, Nico Rizzo.

Asociación de Investigación de la Industria Agroalimentaria (Spain): Jackie Sánchez-Molero, Sara Castelló, Elena Picó, Maite Navarro, Blanca Viadel, José Enrique Carreres, Gema Merino, Rosa Sanjuán, María Lorente, María José Sánchez.

Campden BRI (United Kingdom): Chantal Gilbert, Sarah Thomas, Elaine Allchurch, Peter Burgess.

SIK - Institutet foer Livsmedel och Bioteknik (Sweden): Gunnar Hall, Annika Astrom, Anna Sverkén, Agneta Broberg.

Meurice Recherche \& Development asbl (Belgium): Annick Masson, Claire Lehoux, Pascal Brabant, Philippe Pate, Laurence Fontaine.

Campden \& Chorleywood Food Development Institute (Hungary): Andras Sebok, Tunde Kuti, Adrienn Hegyi.

Productos Aditivos SA (Spain): Cristina Maldonado, Ana Llorente.

Cárnicas Serrano SL (Spain): Emilio García.

Cederroth International $A B$ (Sweden): Holger von Fircks, Marianne Lilja Hallberg, Maria Messerer.

Lantmännen Food RED (Sweden): Mats Larsson, Helena Fredriksson, Viola Adamsson, Ingmar Börjesson.

European Food Information Council (Belgium): Laura Fernández, Laura Smillie, Josephine Wills.

Universidad Politécnica de Madrid (Spain): Marcela González-Gross, Jara Valtueña, David Jiménez-Pavón, Ulrike Albers, Raquel Pedrero, Agustín Meléndez, Pedro J. Benito, Juan José Gómez Lorente, David Cañada, Alejandro Urzanqui, Rosa María Torres, Paloma Navarro.

\section{References}

1. World Health Organization (2003) Diet, Nutrition and the Prevention of Chronic Diseases. Joint WHO/FAO Expert Consultation. WHO Technical Report Series no. 916. Geneva: WHO. 
2. World Health Organization (2004) Global Strategy on Diet, Physical Activity and Health. Geneva: WHO.

3. Viner R \& Macfarlane A (2005) ABC of adolescence - health promotion. BMJ 330, 527-529.

4. Neumark-Sztainer D, Story M, Resnick MD, et al. (1998) Lessons learned about adolescent nutrition from the Minnesota Adolescent Health Survey. J Am Diet Assoc 98, 1449-1456.

5. Moreno LA, Rodriguez G, Fleta J, et al. (2010) Trends of dietary habits in adolescents. Crit Rev Food Sci Nutr 50, 106-112.

6. Arcan C, Neumark-Sztainer D, Hannan P, et al. (2007) Parental eating behaviours, home food environment and adolescent intakes of fruits, vegetables and dairy foods: longitudinal findings from Project EAT. Public Health Nutr 10, $1257-1265$.

7. Ho SY, Wong BYM, Lo WS, et al. (2010) Neighbourhood food environment and dietary intakes in adolescents: sex and perceived family affluence as moderators. Int J Pediatr Obes 5, 420-427.

8. Matthys C, De Henauw S, Maes L, et al. (2006) Adolescents' education and their diet recorded by 7-day food records. Soz Praventivmed 51, 80-90.

9. Hoglund D, Samuelson G \& Mark A (1998) Food habits in Swedish adolescents in relation to socioeconomic conditions. Eur J Clin Nutr 52, 784-789.

10. De Vriendt T, Moreno LA \& De Henauw S (2009) Chronic stress and obesity in adolescents: scientific evidence and methodological issues for epidemiological research. Nutr Metab Cardiovasc Dis 19, 511-519.

11. Dallman MF, Pecoraro NC \& la Fleur SE (2005) Chronic stress and comfort foods: self-medication and abdominal obesity. Brain Behav Immun 19, 275-280.

12. Gibson EL (2006) Emotional influences on food choice: sensory, physiological and psychological pathways. Physiol Behav 89, 53-61.

13. Oliver G \& Wardle J (1999) Perceived effects of stress on food choice. Physiol Behav 66, 511-515.

14. Stone AA \& Brownell KD (1994) The stress-eating paradox multiple daily measurements in adult males and females. Psychol Health 9, 425-436.

15. Habhab S, Sheldon JP \& Loeb RC (2009) The relationship between stress, dietary restraint, and food preferences in women. Appetite 52, 437-444.

16. Kandiah J, Yake M, Jones J, et al. (2006) Stress influences appetite and comfort food preferences in college women. Nutr Res 26, 118-123.

17. Mikolajczyk RT, El Ansari W \& Maxwell AE (2009) Food consumption frequency and perceived stress and depressive symptoms among students in three European countries. Nutr J 8, 31.

18. Zellner DA, Loaiza S, Gonzalez Z, et al. (2006) Food selection changes under stress. Physiol Behav 87, 789-793.

19. Zellner DA, Saito S \& Gonzalez J (2007) The effect of stress on men's food selection. Appetite 49, 696-699.

20. Greeno CG \& Wing RR (1994) Stress-induced eating. Psychol Bull 115, 444-464.

21. Roemmich JN, Wright SM \& Epstein LH (2002) Dietary restraint and stress-induced snacking in youth. Obes Res 10, $1120-1126$.

22. Akerstedt T (2006) Psychosocial stress and impaired sleep. Scand J Work Environ Health 32, 493-501.

23. Asztalos M, Wijndaele K, De Bourdeaudhuij I, et al. (2009) Specific associations between types of physical activity and components of mental health. J Sci Med Sport 12, 468-474.
24. Elder S (2007) The effects of exercise on food intake and body fatness: a summary of published studies. Nutr Rev 65, 1-19.

25. Hart CN, Cairns A \& Jelalian E (2011) Sleep and obesity in children and adolescents. Pediatr Clin North Am 58, 715-733.

26. Austin AW, Smith AE \& Patterson SM (2009) Stress and dietary quality in black adolescents in a metropolitan area. Stress Health 25, 171-178.

27. Nguyen-Rodriguez ST, Chou CP, Unger JB, et al. (2008) BMI as a moderator of perceived stress and emotional eating in adolescents. Eating Behav 9, 238-246.

28. Cartwright M, Wardle J, Steggles N, et al. (2003) Stress and dietary practices in adolescents. Health Psychol 22, 362-369.

29. Kant AK (1996) Indexes of overall diet quality: a review. J Am Diet Assoc 96, 785-791.

30. Waijers PM, Feskens EJM \& Ocké MC (2007) A critical review of predefined diet quality scores. Br J Nutr 97, 219-231.

31. Huybrechts I, Vereecken CA, De Bacquer D, et al. (2010) Reproducibility and validity of a diet quality index for children assessed using a FFQ. Br J Nutr 104, 135-144.

32. Moreno LA, Gonzalez-Gross M, Kersting M, et al. (2008) Assessing, understanding and modifying nutritional status, eating habits and physical activity in European adolescents: the HELENA (Healthy Lifestyle in Europe by Nutrition in Adolescence) Study. Public Health Nutr 11, 288-299.

33. Moreno LA, De Henauw S, Gonzalez-Gross M, et al. (2008) Design and implementation of the Healthy Lifestyle in Europe by Nutrition in Adolescence Cross-Sectional Study. Int J Obes (Lond) 32, Suppl. 5, S4-S11.

34. Beghin L, Castera M, Manios Y, et al. (2008) Quality assurance of ethical issues and regulatory aspects relating to good clinical practices in the HELENA Cross-Sectional Study. Int J Obes (Lond) 32, Suppl. 5, S12-S18.

35. Vereecken CA, Covents M, Matthys C, et al. (2005) Young adolescents' nutrition assessment on computer (YANA-C). Eur J Clin Nutr 59, 658-667.

36. Vereecken CA, Covents M, Sichert-Hellert W, et al. (2008) Development and evaluation of a self-administered computerized 24-h dietary recall method for adolescents in Europe. Int J Obes (Lond) 32, Suppl. 5, S26-S34.

37. Nagy E, Vicente-Rodriguez G, Manios Y, et al. (2008) Harmonization process and reliability assessment of anthropometric measurements in a multicenter study in adolescents. Int $J$ Obes (Lond) 32, Suppl. 5, S58-S65.

38. Cole TJ, Freeman JV \& Preece MA (1998) British 1990 growth reference centiles for weight, height, body mass index and head circumference fitted by maximum penalized likelihood. Stat Med 17, 407-429.

39. Iliescu C, Beghin L, Maes L, et al. (2008) Socioeconomic questionnaire and clinical assessment in the HELENA Cross-Sectional Study: methodology. Int J Obes (Lond) $\mathbf{3 2}$ Suppl. 5, S19-S25.

40. Liberatos P, Link BG \& Kelsey JL (1988) The measurement of social-class in epidemiology. Epidemiol Rev 10, 87-121.

41. Byrne DG, Davenport SC \& Mazanov J (2007) Profiles of adolescent stress: the development of the Adolescent Stress Questionnaire (ASQ). J Adolesc 30, 393-416.

42. De Vriendt T, Clays E, Moreno LA, et al. (2011) Reliability and validity of the Adolescent Stress Questionnaire in a sample of European adolescents - the HELENA study. BMC Public Health 11, 717.

43. Vlaams Instituur voor Gezondheidspromotie (Flemish Institute for Health Promotion and Disease Prevention; VIGeZ) (2008) De actieve voedingsdrieboek: een praktische voedings- en beweeggids (The Active Food Guide Pyramid: 
A Guide for a Daily Balanced Diet and Active Living). Brussels: VIGeZ.

44. Hagströmer M, Bergman P, De Bourdeaudhuij I, et al. (2008) Concurrent validity of a modified version of the International Physical Activity Questionnaire (IPAQ-A) in European adolescents: the HELENA Study. Int J Obes (Lond) 32, Suppl. 5, S42-S48.

45. Martyn-Nemeth P, Penckofer S, Gulanick M, et al. (2009) The relationships among self-esteem, stress, coping, eating behavior, and depressive mood in adolescents. Res Nurs Health 32, 96-109.

46. Jacka FN, Kremer PJ, Leslie ER, et al. (2010) Associations between diet quality and depressed mood in adolescents: results from the Australian Healthy Neighbourhoods Study 1. Aust N Z J Psychiatry 44, 435-442.

47. Oddy WH, Robinson M, Ambrosini GL, et al. (2009) The association between dietary patterns and mental health in early adolescence. Prev Med 49, 39-44.

48. Chang EC (2001) Life stress and depressed mood among adolescents: examining a cognitive-affective mediation model. J Soc Clin Psychol 20, 416-429.
49. Grant KE, Compas BE, Thurm AE, et al. (2004) Stressors and child and adolescent psychopathology: measurement issues and prospective effects. J Clin Child Adolesc Psychol 33, 412-425.

50. Nguyen-Michel ST, Unger JB \& Spruijt-Metz D (2007) Dietary correlates of emotional eating in adolescence. Appetite 49 , 494-499.

51. Goossens L, Braet C, Van Vlierberghe L, et al. (2009) Loss of control over eating in overweight youngsters: the role of anxiety, depression and emotional eating. Eur Eat Dis Rev 17, 68-78.

52. Rudolph KD (2002) Gender differences in emotional responses to interpersonal stress during adolescence. J Adolesc Health 30, 3-13.

53. Macht M (2008) How emotions affect eating: a five-way model. Appetite 50, 1-11.

54. Waladkhani AR \& Hellhammer J (2008) Dietary modification of brain function: effects on neuroendocrine and psychological determinants of mental health- and stress-related disorders. Adv Clin Chem 45, 99-138. 